\title{
Improved Numerical Modelling of Fiber Reinforced Plastics I-Beam from Experimental Modal Testing and Finite Element Model Updating
}

\author{
Asim Kumar Mishra \\ Silicon Institute of Technology, Sambalpur, Odisha, India.
}

\author{
Althaf Mohammed \\ Research \& Development Wing, Indian Register of Shipping, Powai, Mumbai, India.
}

\author{
Sushanta Chakraborty \\ Department of Civil Engineering, Indian Institute of Technology Kharagpur, 721302, India.
}

\begin{abstract}
(Received 18 April 2015; accepted 1 March 2017)
Fiber reinforced plastics (FRP) is increasingly being used in infrastructural applications like bridges, chemical plants etc., where the environment can limit the expected service life of structures made of conventional materials such as reinforced concrete, steel or timber. Advantages of FRP over conventional constructional materials are its high specific strength and specific stiffness, ease with which it can be moulded to various shapes, corrosion resistance, lower lifecycle cost, durability etc. Estimation of accurate dynamic responses of FRP structures is very important from their operation point of view. Such dynamic responses are functions of material properties, boundary conditions, geometry and applied loading. FRP being an anisotropic and layered composite material, a large number of elastic material property parameters are to be determined. Moreover, its structural fabrication and material fabrication at constituent level being one unified process, the actual existing material property parameters may vary considerably from those specified in established standards or determined from characterisation tests. The present approach attempts at establishing a non- destructive technique based on experimental modal testing and finite element model updating to estimate the elastic material parameters of an 'I' beam made of FRP, thereby making the prediction of dynamic responses more accurate. Static load test on the beam and characterisation tests on samples cut from actual structure are conducted to assess the performance of this updating exercise. The current approach can also be used to non- destructively monitor degradations of elastic material properties over time and thus can be used for health monitoring of existing FRP structures.
\end{abstract}

\section{INTRODUCTION}

Use of Fiber Reinforced Plastics (commonly known as FRP) in weight sensitive and high performance applications, such as aerospace, marine, biomedical and sports, is well established due to its high specific strength (strength to weight density ratio) and high specific stiffness (elastic modulus to weight density ratio). Although FRP is being used for repair material to original concrete or steel structures for a long time, its use as main structural members of bridge or building etc. is relatively recent and is economic only in special circumstances. Examples of such applications are structures built in highly corrosive environment of chemical plants or near seashore where conventional building or bridge components made of steel, timber or reinforced concrete have problems that can limit their expected service life. Other applications include replacement of part of existing bridge made of conventional materials with prefabricated FRP structural components in extremely busy places where roadways cannot be closed for long. There are examples of structures made entirely of FRP, e.g. Aberfeldy footbridge over the River Tay in Scotland (Daniel and Ishai 2005). ${ }^{1}$ Application of FRP in infrastruc- ture is promising due to its ability to be moulded to various shapes with very good surface finish, faster fabrication time, superior durability and fatigue strength, good thermal, electrical and acoustic insulation property etc. Davalos et al. (1995, 1996, 1997a, 1997b) have explored approaches to analyse and design pultruded FRP beams in bending and flexural-torsional buckling. $^{2-5}$ A FRP box-girder bridge made of blade angle and T stiffened panels was analysed by Upadhyay and Kalyanaraman (2003). ${ }^{6}$ Kumar et al. (2004) tested FRP pultruded bridge deck, made of square hollow glass and carbon tubes of varying lengths. ${ }^{7}$ Wael (2010) presented a stability model for the local buckling of pultruded fiber reinforced polymer structural shapes subjected to eccentric compression. ${ }^{8}$ Esfandiari et al. (2010) have put forward a parameter estimation approach using response sensitivities with respect to the change of mass and stiffness, evaluated from the decomposed frequency response functions. ${ }^{9}$ Hollaway (2010) discusses the infrastructural applications of advanced polymer composite materials over the past four decades. ${ }^{10}$ The behavior and performance of ultra thick laminate component of T-sections manufactured with non-crimped fabrics (NCF) was investigated by Zimmermann et al. (2010) using a 3D modeling approach. ${ }^{11}$ Amir et 
al. (2011) modelled a pultruded FRP hat section box girder. ${ }^{12}$ Contribution of shear deformation on the lateral buckling behavior of open cross-sections pultruded FRP beams were investigated by Ascione et al. (2011). ${ }^{13}$ Feo et al. (2013) presented experimental and numerical results of investigation on one of the major structural issues termed as the "influence zone" that defines the strength limit-state of pultruded fiber- reinforced polymer (PFRP) profiles. ${ }^{14}$ A state-of-the art review of the analytical and numerical studies performed with the aim of predicting the strength, the load-deformation response and the failure mode of rehabilitated RC members was reported by Napoli et al. (2013). ${ }^{15}$ A carbon fiber based FRP floor panel, designed as a pultruded beam with an open cross-section, was investigated by Gao et al. (2013) and it was observed that the pultruded fabrication has relatively weak strength in the transverse matrix and through thickness direction. ${ }^{16}$ Cardoso et al. (2015) developed a simple accurate equation to determine the local buckling critical stress of pultruded GFRP I-sections. ${ }^{17}$ It appears that the current literature is still scanty about the dynamic behavior of such FRP structural forms.

Static and dynamic behaviour of FRP structures are functions of physical properties, existing boundary conditions and applied loading. Unlike isotropic materials, material fabrication and structural fabrication are a unified process in FRP composites. Moreover, manufacturing and curing processes differ considerably in various applications. Thus, the material property parameters may differ significantly from those specified nominally by the manufacturer or obtained from established standards or determined from quasi-static characterisation tests. In most cases, these characterisation test results also have substantial variations, making the material property as one of the most uncertain parameter in predicting dynamic behaviour. Moreover, the construction of FRP structural components is still very much dependent upon skill of labour and is another source of uncertainty.

Unlike isotropic materials, experimental quasi-static characterisation of FRP composite materials is time consuming as a large number of parameters need to be measured. It is even more difficult to assess the global material properties of structural components from constituent level properties, such as from fiber and matrix properties. It would be best if a FRP structure can be tested as a whole and the overall existing material properties verified in situ through a well posed inverse problem. All subsequent global prediction of behaviour will match much more accurately with observations.

Correction of finite element models by processing dynamic test data is an active area of research. ${ }^{18}$ There are numerous examples of inverse problems for the determination of average material properties of composite materials from dynamic testing. Special attention is given in current literature for the estimation of the four in-plane elastic constants viz. $E_{1}, E_{2}, G_{12}$ and $\nu_{12}$ of orthotropic materials from experimentally measured natural frequencies and mode shapes. Early examples can be found with the work of De Wilde et al., ${ }^{19}$ Sol, ${ }^{20}$ Deobald and Gibson, ${ }^{21}$ Grédiac and Paris. ${ }^{22}$ Mota Soares et al. (1993) used plate shaped specimens to identify layered properties of composites. ${ }^{23}$ Larsson $^{24}$ presented an iterative method to determine all four in-plane elastic constants of thin oriented strand board (OSB) from a single modal test. The distinct feature of this paper is that the shear modulus is estimated from twisting modes and the Poisson's ratio is determined separately from compression mode. Cugnoni et al. identified both in-plane and transverse elastic constitutive properties of composite laminates from a single non-destructive test. ${ }^{25}$ Out of many optimization algorithms, gradient based optimization techniques are conveniently used to estimate the material parameters, due to their faster convergence. Collins et al. were the first to introduce one of the most popular gradient based approaches, viz. the Inverse Eigensensitivity Method (IEM) for model updating. ${ }^{26}$ Later, Chen and Garba modified Collin's statistical approach into a matrix perturbation method to make it more convenient for practical use. ${ }^{27}$ Dascotte applied this approach to determine the in-plane elastic constants of vertically stiffened composite cylindrical shells. ${ }^{28}$ Mishra and Chakraborty have recently applied the same methodology to estimate the material properties of FRP plates under clamped boundary conditions. ${ }^{29}$ Also they have estimated the constituent level elastic properties for the materials used. ${ }^{30}$ In the present investigation, the same gradient based IEM implemented through commercially available software FEMtools ${ }^{31}$ has been explored. The current literature related to application of model updating to estimate elastic material parameters advocates small rectangular plate type of specimens in free-free boundary conditions. Application of model updating to real existing civil engineering structural forms is seen to be very rare.

An investigation has been carried out here to determine the representative average material parameters of a fabricated FRP 'I' beam from experimentally determined modal parameters and finite element predictions using model updating techniques. The ultimate goal is to prepare a precise numerical model to predict dynamic responses more accurately for any such FRP structure with the help of updated parameters. The results have been verified by quasi-static characterisation tests of samples cut from the actual structure later. Also, the entire FRP beam is tested under static load to confirm the overall stiffness and strength achieved. The actual procedure of modal testing and updating takes very less time as compared to the characterisation tests and gives opportunity for rapid assessment to monitor the structure's health from time to time non-destructively. The effect of damping is neglected in the present investigation. This is justified because of the fact that damping shifts the resonant frequencies very little in the frequency axis while measuring the frequency response functions in modal domain. However, this is to be remembered that if the actual response magnitude is to be predicted, estimation of damping must be done as accurately as possible. Since damping depends upon material behaviour, looseness at supports, or on environmental effects such as existence of surrounding fluid etc., a global average damping model is used at system level with the aid of proper measurement. Velocity proportional equivalent viscous damping model is generally agreed upon to represent appropriate damping behaviour of structures. Since the present investigation is totally performed in frequency domain after doing the Fourier transform of the time responses, the issue of appropriate modelling of damping does not affect the results significantly. For this reason, most of the current literature related to estimation of material parameters of layered composites apply the finite element model updating consid- 


\begin{tabular}{l}
\hline \hline Table 1. Geometrical properties for the fabricated FRP beam. \\
\begin{tabular}{|c|c|c|c|c|c||}
\hline $\begin{array}{c}\text { Density } \\
\left(\mathrm{kg} / \mathrm{m}^{3}\right)\end{array}$ & $\begin{array}{c}\text { Sectional } \\
\text { Area } \\
(A)\end{array}$ & $\begin{array}{c}\text { Depth of } \\
\text { Section } \\
(D)\end{array}$ & $\begin{array}{c}\text { Width of } \\
\text { Flange } \\
(W)\end{array}$ & $\begin{array}{c}\text { Flange } \\
\text { Thickness } \\
\left(T_{f}\right)\end{array}$ & $\begin{array}{c}\text { Web } \\
\text { Thickness } \\
\left(T_{w}\right)\end{array}$ \\
\hline 1625 & $4800 \mathrm{~mm}^{2}$ & $220 \mathrm{~mm}$ & $160 \mathrm{~mm}$ & $10 \mathrm{~mm}$ & $8 \mathrm{~mm}$ \\
\hline
\end{tabular}
\end{tabular}

ering the modes to be undamped, although in actual the FRP types of structures have considerable damping. The modal testing has been performed both in free- free and simply supported boundary conditions to extract the free vibration behaviour in undamped modes here. However, it is suggested that proper damping model be included in future similar studies where reproduction of actual response prediction is necessary. Accurate prediction of actual response is absolute necessity for structural control and serviceability assessment related problems. This is also mandatory where health monitoring or condition assessment studies are conducted.

\section{FABRICATION OF SAMPLE FRP BEAM}

In this present investigation, hand lay-up procedure was adopted as it gives the opportunity to observe the lower limit of achievement in terms of strength and stiffness of such structural component. A FRP 'I' shaped beam of $2 \mathrm{~m}$ span was fabricated. Four numbers of steel channel sections of $70 \mathrm{~mm}$ $\times 200 \mathrm{~mm}$ were selected to act as the rigid formwork for the casting and to give superior surface finish, thereby giving less variations of geometric parameters. This is to be remembered that in actual practice, such smoothness may not be available for formworks. Thin Teflon sheets were used to prevent the direct contact between the FRP sheets and the steel formwork and also for the easy removal of formwork at a later stage. Araldite CY230 and Hardener HY951 were mixed in 9:1 proportion by weight to produce the Epoxy matrix. E-Glass fiber woven mats were laid layer by layer with matrix in between the layers in such a manner to get an I section of $160 \mathrm{~mm} \times$ $220 \mathrm{~mm}$ with flange and web thicknesses of $10 \mathrm{~mm}$ and $8 \mathrm{~mm}$ respectively. For doing so, 24 number of FRP sheets having dimensions $2000 \mathrm{~mm} \times 368 \mathrm{~mm}$ were laid layer by layer with matrix in between the layers to build two ' $\mathrm{C}$ ' shaped sections of 12 layers each with half the web thickness $(4 \mathrm{~mm})$. These two FRP ' $C$ ' sections were put back to back immediately with the same matrix in between to get an I-section with flange thickness as half the desired web thickness $(4 \mathrm{~mm})$. The rest of the flange thickness $(6 \mathrm{~mm})$ was made immediately by laying 18 layers of FRP sheets $(6 \mathrm{~mm})$ of dimension $2000 \mathrm{~mm} \times 160 \mathrm{~mm}$ at the top as well as at the bottom. The whole assembly was kept in position with the help of external supports as shown in Fig. 1.

After curing at room temperature, the formwork was removed with proper care. Some minor finishing works such as cleaning, grinding and polishing was necessary to achieve smooth surfaces of the fabricated FRP beam. The finished FRP beam has been shown in Fig. 2. The final geometrical properties of the beam are given in Table 1 .

The entire fabrication process suggested in this paper is very simple, requires minimum training and is much cost effective as compared to other mechanised processes, such as pultrusion process etc.

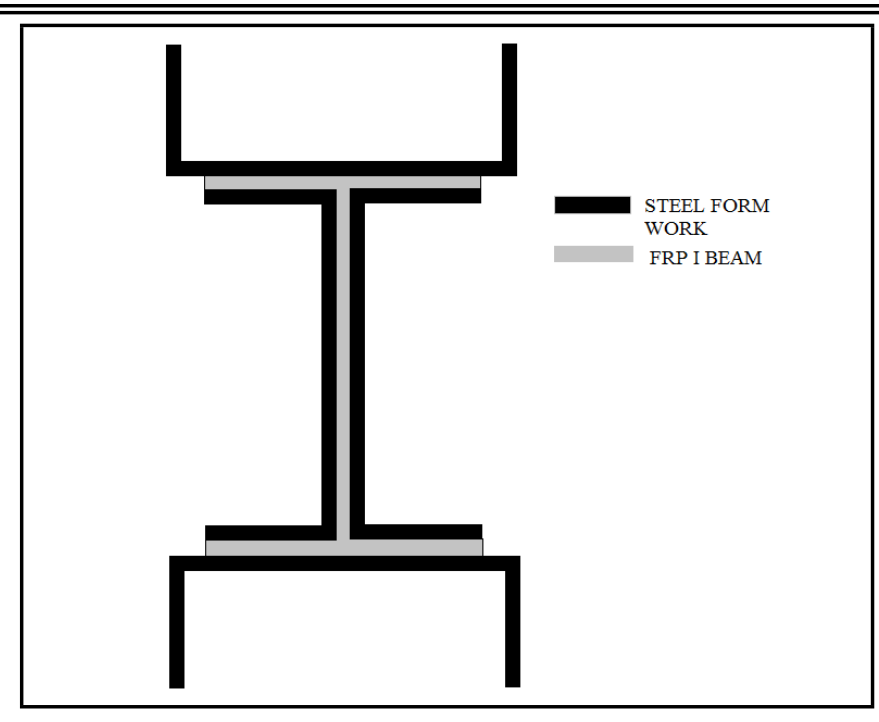

Figure 1. Arrangement of Formwork.

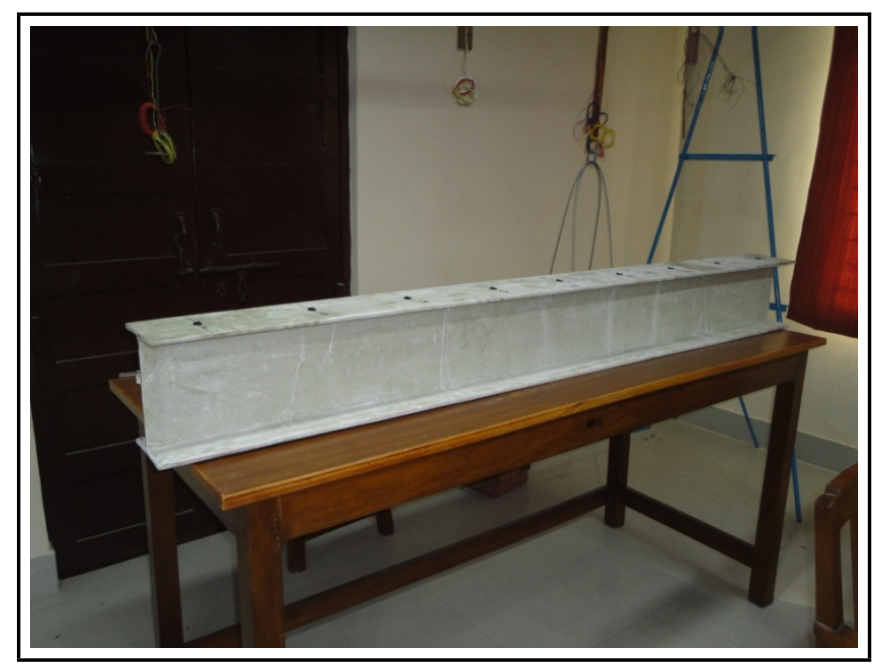

Figure 2. Fabricated FRP beam.

\section{MODAL TESTING OF FRP BEAM}

Modal testing was carried out on the 'I' beam in both freefree and simply supported boundary conditions. It is to be mentioned that for the free-free boundary conditions, the full 2 meter length was available as effective span, whereas, in simply supported case, the effective span reduces to 1.8 meter in order to provide adequate supports at both ends. Broad band excitation was imparted to the structure with the help of a roving impact hammer (B\&K 8206-002) fitted with a force transducer at its tip and the responses at a single reference point were picked up by an accelerometer (DeltaTron 4507). The time domain force and response signals were Fourier transformed and stored in a spectrum analyser (B\&K 3560-C-L4). Pulse LabShop ${ }^{32}$ software was used for computing the frequency response functions (FRFs) and the software ME'scopeVES ${ }^{33}$ was used for estimating the modal parameters, i.e. the frequencies and mode shapes using multi degrees of freedom curve fitting algorithm. These are the modal parameters from which the material elastic parameters will be updated using inverse problem. 


\subsection{Modal Testing under Free-Free Boundary Conditions}

The FRP beam was freely suspended with a cluster of rubber bands as shown in Fig. 3 to nearly simulate the free-free boundary. The hanging points are a compromise with respect to the nodal points in most of the modes of interest-effort has been made to keep the supports as near to the node points as possible for better estimate of modal parameters. Figure 4 depicts the schematic diagram for the layout of the testing arrangement. Three experimental flexural mode shapes are shown in Fig. 5. The stiffness of the rubber bands were found to be $0.237 \mathrm{kN} / \mathrm{m}$ which is quite less than the structural stiffness of the beam which is of the order of approximately $5000 \mathrm{kN} / \mathrm{m}$, as is later predicted from static testing of the entire beam. Again, the frequency of oscillation of this suspended system is of the order of fraction of $1 \mathrm{~Hz}$, whereas the fundamental frequency of vibration starts from well above $200 \mathrm{~Hz}$ for the bending modes of the FRP beam. Hence, such arrangement of supports practically can replicate well the free boundary conditions. Also, it is to be mentioned that a bigger capacity hammer can increase the frequency range of interest but runs the risk of driving the structure to nonlinear responses. In the same manner, using steel tip can impart local deformation at the point of contact, although the frequency range increases. The current formulation of modal test is not suitable if nonlinearity is present.

For this particular investigation related to the test in free boundary conditions, the second mode was not measured with sufficient accuracy and therefore has not been presented here. The reason for this can be guessed if the locations of the supports are closely looked into - the support points of the second mode were not very close to the node points, thereby making the measurements somewhat noisy, as the signal to noise ratio deteriorate for the second mode while testing in freefree boundary conditions. When the excitation or the response points are very near to the node points, then also the measurement quality deteriorates. Selection of the support points were made thinking about all the modes in range. So, the excitation points were tried at various locations. However, in this case changing the measurement point could not improve the results much. The other modes were measured well and presented. In case all modes are to be measured accurately, then separate hanging points could be used for each mode while testing, avoiding the node points as excitation or response point for that mode. However the arrangement of the present investigation was restricted to a single modal test. It is suggested that for fruitful application of finite element model updating exercise, the modal data be extracted for each individual mode separately, either by changing the hanging position for supports or by deploying other techniques of excitation, such as a shaker in direct contact mode. However, the modal testing time will increase considerably in such cases.

\subsection{Modal Testing under Simply Supported Boundary Conditions}

The FRP beam was simply supported at two ends keeping a clear span of $1.8 \mathrm{~m}$ with special knife-edge fixtures to allow only rotation at supports Fig. 6.The first four experimental modes are shown in Fig. 7.

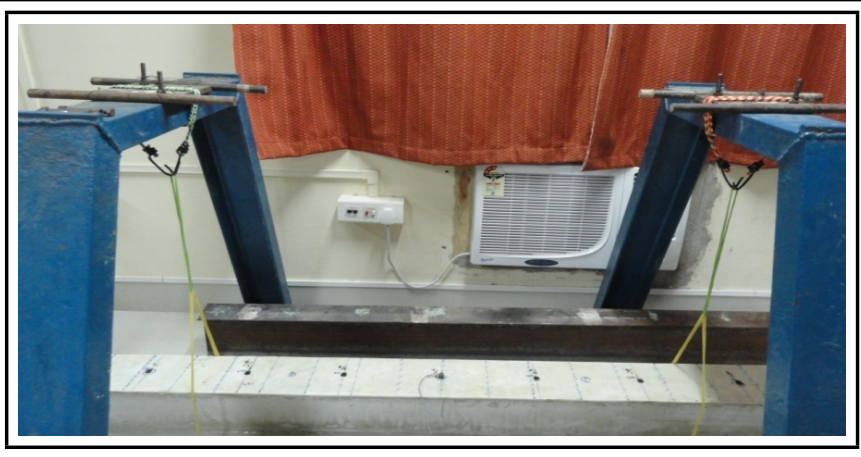

Figure 3. FRP beam suspended with rubber bands to simulate free-free boundary.

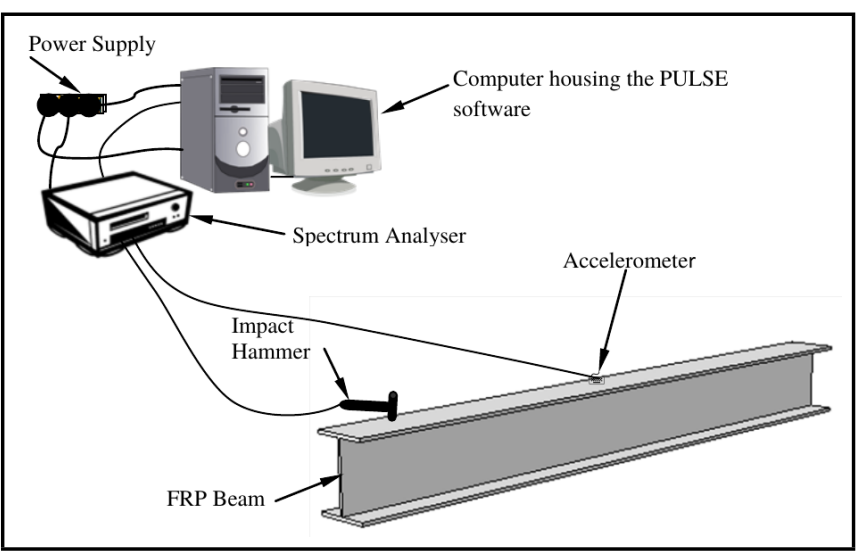

Figure 4. Schematic diagram of the modal testing arrangement.

\section{FINITE ELEMENT MODELLING TO COMPUTE FREE VIBRATION RESPONSES}

The beam was also modelled using finite element software ABAQUS $^{34}$ implementing 8 noded shell elements, having 5 degrees of freedom per node and the eigensolutions were carried out for the free-free boundary conditions implementing the Block Lanczos algorithm. The material properties have been selected nominally from established standards. Equivalent single layer theory has been used to compute the rigidity matrix of the FRP laminates. ${ }^{1}$ The eigensolutions were also obtained for the simply supported boundary conditions and the frequencies and mode shapes corresponding to the experimentally observed flexural modes are shown in Fig. 8. There are many more modes due to small relative movement of flanges and webs which are not global bending modes; hence are not considered here.

The observed frequencies are compared with numerically obtained frequencies for both free-free boundary conditions and simply supported boundary conditions and are reproduced in Table 2. It is immediately apparent that there exist considerable differences between these two sets of results. The causes of such differences need to be explored and the parameters responsible are to be updated. Since the predicted frequencies are consistently more as compared to the observed modes, for particular correlated pair of modes, it appears that the numerical model is likely to be stiffer than actual. Thus, the numerical model needs its stiffness parameters to be updated. The elastic material parameters are selected as the set of parameters to be 


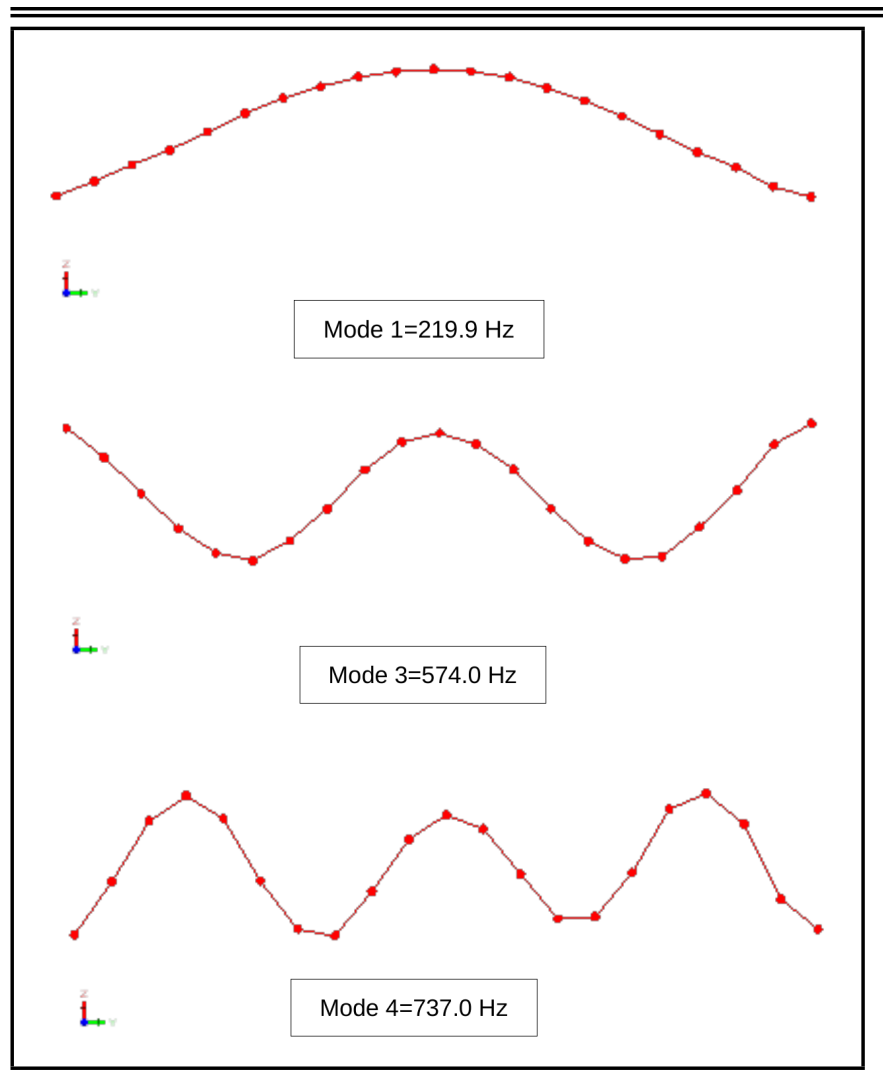

Figure 5. Observed modes for the free-free beam.

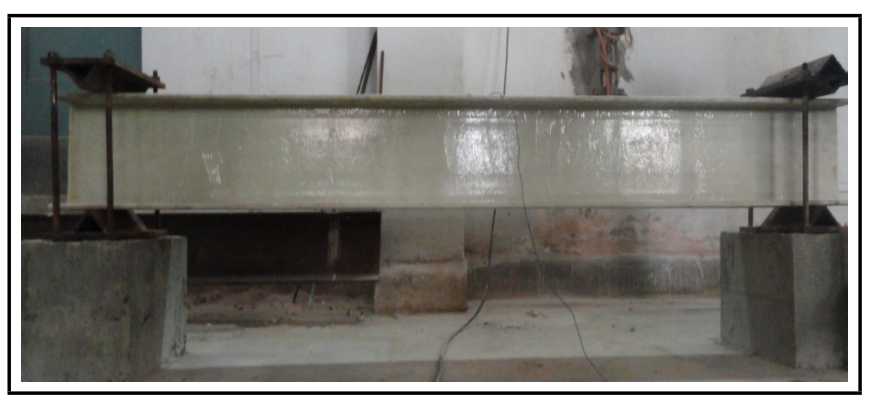

Figure 6. Simply-supported FRP beam.

Table 2. Comparison of frequencies of the FRP 'I' beam.

\begin{tabular}{||c|c|c|c|c||}
\hline $\begin{array}{c}\text { Mode } \\
\text { No. }\end{array}$ & \multicolumn{2}{|c|}{$\begin{array}{c}\text { Free-Free } \\
\text { boundary conditions }\end{array}$} & \multicolumn{2}{c|}{$\begin{array}{c}\text { Simply supported } \\
\text { boundary conditions }\end{array}$} \\
\hline & $\begin{array}{c}\text { Experimentl } \\
(\mathrm{Hz})\end{array}$ & $\begin{array}{c}\text { Numerical } \\
(\mathrm{Hz})\end{array}$ & $\begin{array}{c}\text { Experimentl } \\
(\mathrm{Hz})\end{array}$ & $\begin{array}{c}\text { Numerical } \\
(\mathrm{Hz})\end{array}$ \\
\hline First & 219.9 & 246.93 & 124.5 & 140.72 \\
\hline Second & - & 488.79 & 338.5 & 396.23 \\
\hline Third & 574.0 & 671.09 & 496.1 & 612.15 \\
\hline Fourth & 737.0 & 846.95 & 727.0 & 833.40 \\
\hline
\end{tabular}

updated here from careful review of all geometric and material parameters, boundary conditions and their relative uncertainties.

\section{STATIC TEST ON FRP BEAM}

Once the dynamic testing was over, static test of the FRP beam was carried out to assess the load-deformation characteristics in linear range. The four point bending test was carried out using a universal testing machine (UTM) to impart a constant bending moment within most of its span in the middle (Fig. 9). The clear span of the beam was $1.6 \mathrm{~m}$. Three dial

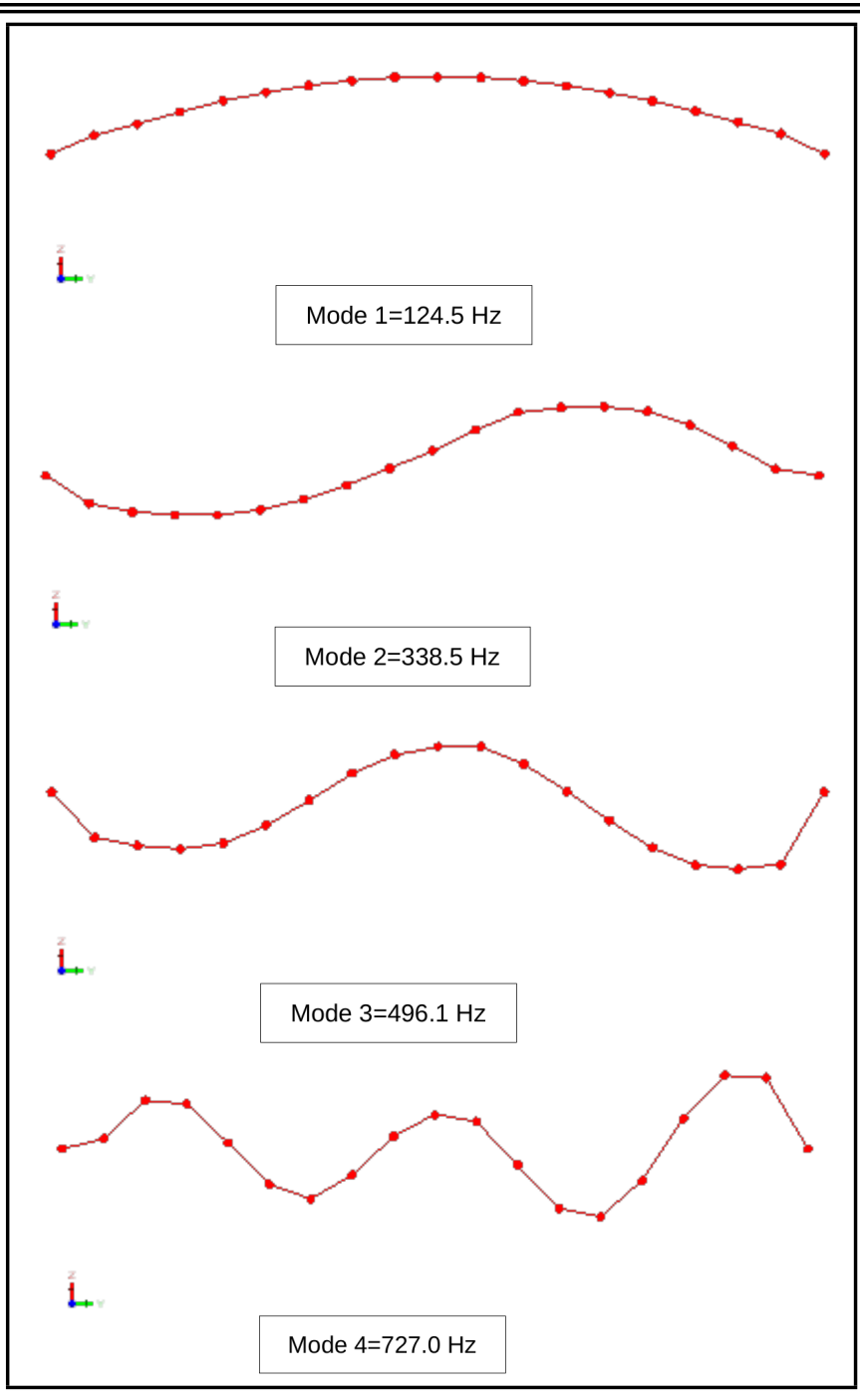

Figure 7. Observed modes for the simply supported beam.

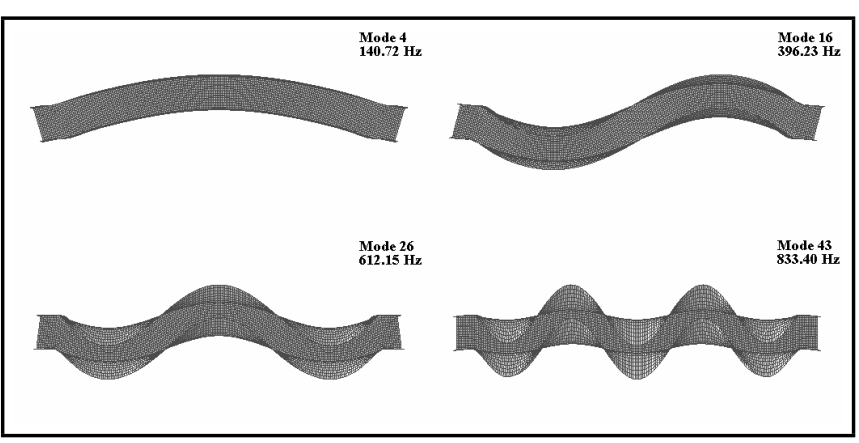

Figure 8. Numerical mode shapes in simply supported boundary conditions.

gauges were put at one third, middle and two third positions to observe the deflection characteristics. The strain gauges were put along the depth of the beam at the mid span to ascertain the assumption of linear strain variation, i.e. plane sections remain plane after bending remains valid during testing. The load deflection curves are shown in Fig. 10.

Although it was not the primary objective, the beam was loaded further until failure and an ultimate load of $52 \mathrm{kN}$ with a deflection of $14.7 \mathrm{~mm}$ at the centre before failure was recorded. The moment carrying capacity was estimated to be $13.87 \mathrm{kN} \cdot \mathrm{m}$. The average equivalent modulus of elasticity of the material was found out to be approximately $15.8 \mathrm{GPa}$. Dur- 


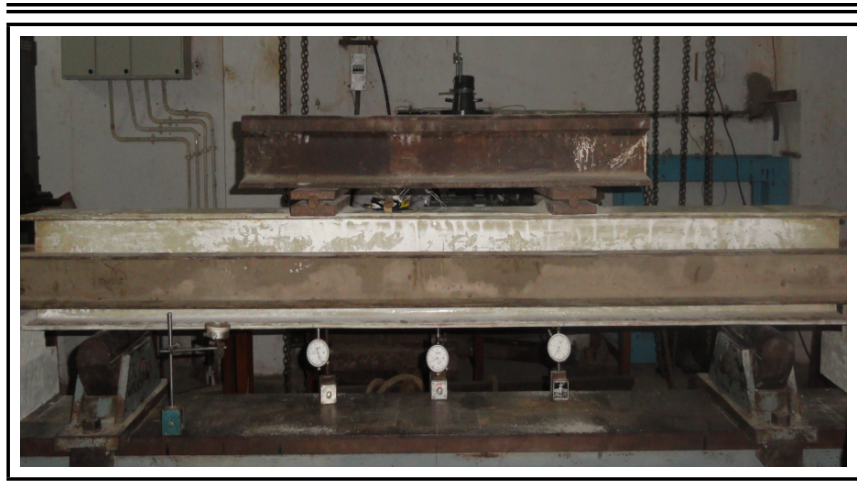

Figure 9. Experimental set up for four point bending test.

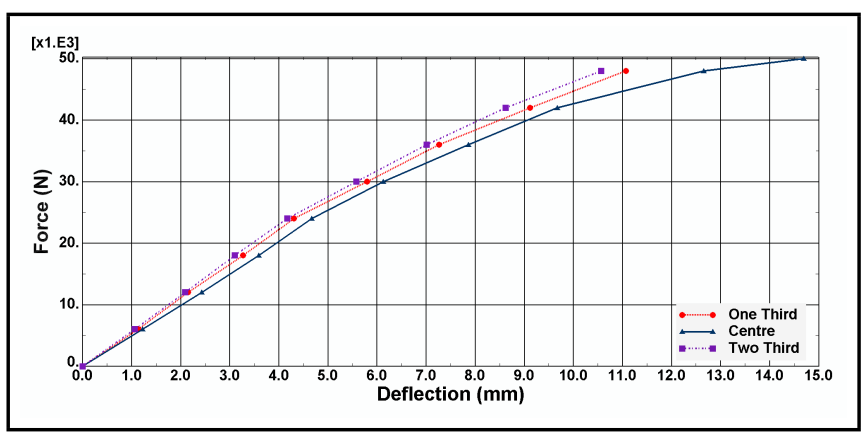

Figure 10. Static load-deflection graph.

ing the present testing, failure took place by crushing of top flange, followed by separation of interface between flange and web. The load deformation characteristics at the initial stage of loading remained linear.

\section{UPDATING OF FINITE ELEMENT MODEL TO ESTIMATE MATERIAL PARAMETERS}

\subsection{Mathematical Formulation and Software Implementation of Updating Process}

The modes computed from finite element analysis were paired with corresponding experimentally observed modes using Modal Assurance Criteria (MAC). ${ }^{35}$ Here, the main source of error is believed to be from the uncertainties in elastic material properties and they are selected as the parameters to be updated.

A sensitivity based inverse approach has been implemented through the commercially available model updating software FEMtools for the parameter estimation. The linearized first order approximation of the relationship between measurable (output) eigenvalues and eigenvectors and (input) average material parameters, can be represented through a Taylor series approximation: ${ }^{27}$

$$
\left\{f_{i}(r)\right\}=\left\{f_{i}(\bar{r})\right\}+\left[\frac{\partial f\left(r_{i}\right)}{\partial r_{i}}\right]_{r=\overline{r_{i}}}\left(r_{i}-\overline{r_{i}}\right) ;
$$

where, $r_{i}$ represent the parameters to be identified (i.e. the in-plane elastic parameters), $\bar{r}_{i}$ are the a-priori estimate of $r_{i}$, $f_{i}(r)$ is measured eigenvalues and eigenvectors of the ' $\mathrm{I}$ ' beam, $f_{i}(\bar{r})$ is modal properties of initial finite element model of the beam, and $\left[\frac{\partial f\left(r_{i}\right)}{\partial r_{i}}\right]_{r=\overline{r_{i}}}$ is first order sensitivity matrix (Jacobian matrix), of eigenvalues and eigenvectors of the beam with respect to the material parameters to be estimated.

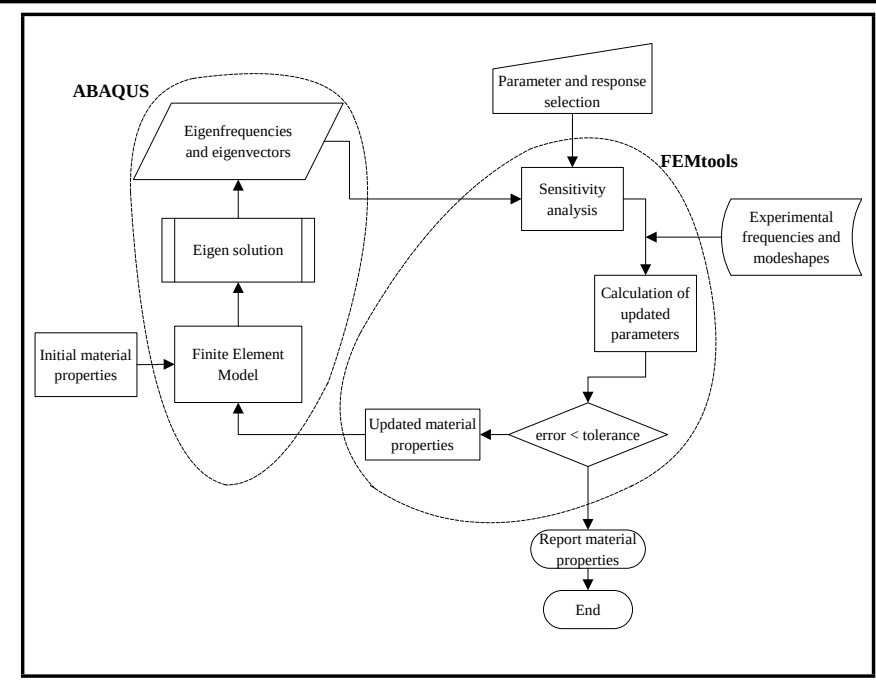

Figure 11. Flow chart of the updating algorithm.

The Eq. (1) can be expressed as:

$$
\{\Delta f\}=[S]\{\Delta r\}
$$

where, $\{\Delta f\}=f\left(r_{i}\right)-f\left(\bar{r}_{i}\right),\{\Delta r\}=r_{i}-\bar{r}_{i}$, and $[S]=\left[\begin{array}{ll}\partial f\left(r_{i}\right) & \\ & \partial r_{i}\end{array}\right]_{r=\overline{r_{i}}}$.

The residual error vector at any iteration can be expressed as:

$$
\{\Delta\}=\{\Delta f\}-[S]\{\Delta r\} .
$$

The IEM tries to minimize the above error function in least square sense, thereby implementing $\{\Delta r\}$ change to the parameter $r_{i}$.

A new $\{r\}$ is generated at every iteration using the equation:

$$
\{r\}_{i+1}=\{r\}_{i}+\{\Delta r\}_{i}
$$

The procedure is repeated with updated in-plane material parameter values, until the square of the error between the numerical and experimental modes falls within a predetermined margin of error; $\varepsilon$.

$$
\{\Delta\}^{T}\{\Delta\} \leq \varepsilon .
$$

IEM requires that initial guesses are made for the parameters to start the proposed iterative algorithm. This is done by generating uniformly distributed random values of the inplane elastic parameters within selected realistic upper and lower bounds. Material properties were estimated through a sensitivity based algorithm implemented by the commercially available software FEMtools using the finite element program ABAQUS as the external solver - ABAQUS is called by the FEMtools whenever there is an eigensolution needed. The flowchart of the software implementation has been shown in Fig. 11.

\subsection{Implementation of Updating Algorithm to Estimate In-plane Material Parameters}

The FRP laminated composite used in the present investigation has almost negligible difference in elastic properties in 


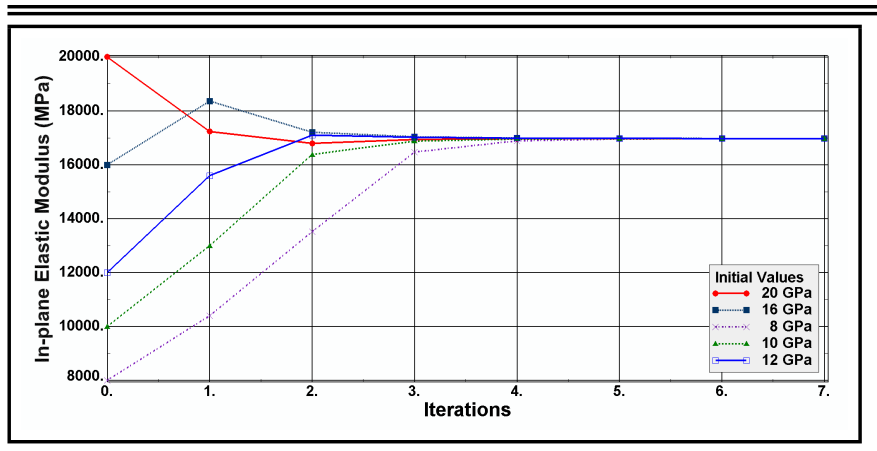

Figure 12. Convergence plot for $E_{1}$ and $E_{2}$ for the free-free beam.

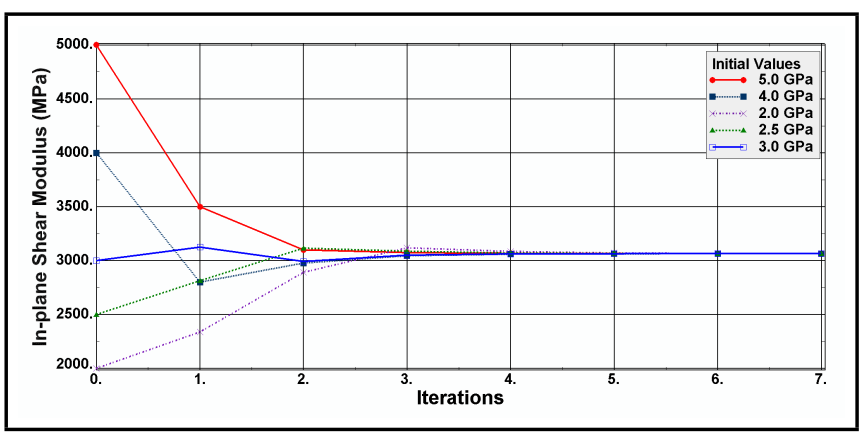

Figure 13. Convergence plot for $G_{12}$ for the free-free beam.

longitudinal and transverse directions, thus the elastic material property parameters to be updated can be assumed to be same for the 'I' beam in longitudinal and transverse directions. The in-plane Poisson's ratio can only be updated successfully from measured modal properties, if sufficient number of torsional modes can be excited during modal testing. However, in the present investigation only first few flexural modes were measured. Thus the value of Poisson's ratio was taken nominally to be 0.26 for the numerical simulations and later almost the same value was found from the characterisation tests.

The parameters were estimated iteratively and the convergence plots of the material parameters from selected initial values with wide ranges of variations are presented in Figs. 12 and 13 for the free-free boundary conditions.

The convergences of $E_{1}$ as well as $E_{2}$ together were to a value of $16.97 \mathrm{GPa}$, with the shear modulus $G_{12}$ converging to $3.06 \mathrm{GPa}$ for free-free boundary conditions. It is to be mentioned that the algorithm is framed to solve the inverse problem in an over-determined manner. Thus the number of frequencies and mode shape coordinates need to be sufficiently high with respect to the parameters to be estimated for unique solution in a least square sense. That's the reason other higher modes were found to be acceptably accurate enough to participate in model updating, even when the second mode could not be measured with sufficient accuracy. Use of only the fundamental (first) mode runs the risk that contribution of all higher modes would not reflect in the parameter estimation. The second mode itself could have been measured with greater accuracy by shifting of the suspension cord a bit and accepting somewhat more error into the other modes. The updating exercise with simply supported boundary conditions showed a convergence of $E_{1}$ and $E_{2}$ to approximately $17.95 \mathrm{GPa}$ and the shear modulus to approximately 3.0 GPa. The review of the modal testing procedure in both free-free and simply supported

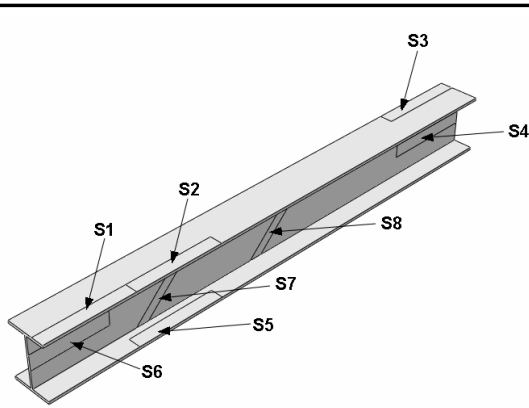

Figure 14. Location map for extracting samples for characterisation tests.

Table 3. Material parameters from characterisation tests.

\begin{tabular}{|c|c|c|}
\hline Sample Designation & Tested for & Value \\
\hline S1 & Young's modulus (E1) & $15.5 \mathrm{GPa}$ \\
\hline S2 & Young's modulus (E1) & $15.77 \mathrm{GPa}$ \\
\hline S3 & Young's modulus (E1) & $16.92 \mathrm{GPa}$ \\
\hline S4 & Young's modulus (E1) & $16.74 \mathrm{GPa}$ \\
\hline S5 & Young's modulus (E1) & $15.93 \mathrm{GPa}$ \\
\hline S6 & Poisson's ratio & 0.29 \\
\hline S7 & Young's modulus in 45 & $9.87 \mathrm{GPa}$ \\
\hline S8 & Young's modulus in 45 & $10.2 \mathrm{GPa}$ \\
\hline
\end{tabular}

conditions suggests putting more confidence on the results obtained from the free-free condition. It appears that the simply supported boundary with knife edge support has provided at least some resistances to rotation, thereby making the prediction of Young's modulus slightly higher than that obtained in free boundary conditions. It can only be verified by conducting characterisation tests for the above material constants. However, in all cases the convergences are found to be monotonic and unique from a varied set of initial starting values of parameters.

\section{QUASI-STATIC CHARACTERIZATION TESTS TO CONFIRM MATERIAL PROPERTIES}

Specimens have been prepared for the quasi-static characterisation tests by cutting the actual beam and the tests were conducted as per ASTM D3039/D3039M ${ }^{36}$ using a Universal Testing Machine (Tinius-Olsen, Super 'L' series UTM) to determine the in-plane elastic properties $\left(E_{1}, E_{2}, G_{12}\right.$ and $\left.\nu_{12}\right)$ of the FRP laminate. The practical available lengths of samples in this existing structural component were slightly smaller than that specified in the above standard. Samples have been drawn from different locations of the FRP beam as shown in Fig. 14. Coupons at $45^{\circ}$ orientations to the principal material axis were cut from the web only (as there were insufficient length available in flanges) and tested to determine the shear modulus and the formula used was taken from literature ${ }^{37}$ and is reproduced here:

$$
G_{12}=\frac{1}{\frac{4}{E_{45}}-\frac{2\left(1-\nu_{12}\right)}{E_{1}}} .
$$

The Poisson's ratio was determined by measuring the strains in both longitudinal and transverse direction with the help of two extensometers. The test results are given in Table 3. 
Table 4. Discrepancies between observed frequency parameters (EMA) and those determined numerically (FEA) using updated material parameters from free-free test.

\begin{tabular}{|c|c|c|c|c|c|c||}
\hline $\begin{array}{c}\text { Mode } \\
\text { No. }\end{array}$ & \multicolumn{3}{|c|}{$\begin{array}{c}\text { Free-Free } \\
\text { boundary conditions }\end{array}$} & \multicolumn{3}{c|}{$\begin{array}{c}\text { Simply supported } \\
\text { boundary conditions }\end{array}$} \\
\hline & $\begin{array}{c}\text { EMA } \\
(\mathrm{Hz})\end{array}$ & $\begin{array}{c}\text { FEA } \\
(\mathrm{Hz})\end{array}$ & $\begin{array}{c}\text { Error } \\
(\%)\end{array}$ & $\begin{array}{c}\text { EMA } \\
(\mathrm{Hz})\end{array}$ & $\begin{array}{c}\text { FEA } \\
(\mathrm{Hz})\end{array}$ & $\begin{array}{c}\text { Error } \\
(\%)\end{array}$ \\
\hline 1 & 219.9 & 218.39 & -0.68 & 124.5 & 124.27 & -0.18 \\
\hline 2 & - & - & - & 338.5 & 336.38 & -0.62 \\
\hline 3 & 574.0 & 574.11 & 0.00 & 496.1 & 519.31 & 4.67 \\
\hline 4 & 737.0 & 743.66 & 0.90 & 727.0 & 719.82 & -0.98 \\
\hline
\end{tabular}

$G_{12}$ is calculated from the expression in Eq. (6) and was found to be $3.13 \mathrm{GPa}$ and $3.26 \mathrm{GPa}$ respectively for samples S7 and S8.

\section{REGENERATED NATURAL FREQUENCIES WITH UPDATED MATERIAL PARAMETERS}

With the updated properties of the material parameters from the free-free test results, the frequencies and mode shapes were computed using the finite element model. The reminiscent errors in the frequencies for the free-free beam and simplysupported conditions are reported in Table 4.

From the variations in material properties determined from the characterisation tests, it is found that near the supports, the material property values are somewhat higher. Due to scanty data it was difficult to arrive at any agreeable statistical characteristics of these variations. However, the regenerated modal properties using the updated material parameters from freefree test results are very close to the observed modal characteristics. This indicates that if a set of global material property parameters is to be agreed upon, it is this set of updated parameters which bring the observed modal characteristics into closer agreement with modelling.

The updated material parameters from the free-free modal test were found to be more acceptable as compared to the simply supported test results. In simply supported case, the frequencies were not reproduced exactly to the observed values even when the updated parameters from free-free results were used, but the errors were reduced much. The remaining discrepancy may be due to the boundary conditions only. If the realistic boundary conditions can be incorporated into the model, the experimental observation is expected to be closer to finite element modelling, with simply supported boundary conditions. The actual existing boundary condition can be determined from model updating by selecting the boundary flexibility as parameters as well but not explored here. Reproduction with the help of the updated model of time responses to compare with the measured time responses can only be made if there is a sufficiently accurate and validated damping model. At present this has been kept as a future scope for similar investigation. Although such direct comparison of time responses are difficult to be used for parameter estimation, but can be used for condition assessment and health monitoring exercise as an avenue for anomaly detection between observation and modelling.

\section{CONCLUSIONS}

An attempt has been made to produce a more accurate updated model of a FRP 'I' beam from measured dynamic responses by estimating the most uncertain in-plane material properties in free-free and simply supported boundary conditions. For this, a FRP beam was fabricated using the hand layup process which is very simple to replicate and is also very cost effective as compared to any mechanised process. The methodology of model updating is observed to work acceptably in the environment of modal and spatial sparsity, as selective modal coordinates and only a few selected frequencies were used for updating. The demand on number of modes to be measured can be drastically reduced provided quality mode shape data can be acquired. It was found from model updating and characterisation tests that if a set of global material parameters is to be agreed upon, the material constants obtained from model updating in free-free condition can be most appropriate. This is difficult to determine from characterisation tests, where substantial local variations in material and geometric properties exist. Once an accurate updated model of such FRP structure is made, this can be used for keeping track on its performance due to operational and live loads and can also be used for regular condition assessment and health monitoring. These goals are impossible to achieve with approximate models having uncertainties in material or other parameters

\section{REFERENCES}

1 Daniel, I. M. and Ishai, O. Engineering Mechanics of Composite Materials, Oxford University Press, New York, 2005, 2nd ed.

2 Davalos, J. F. Salim, H. A. Qiao, P. Lopez-Anido, R. and Barbero, E. J. Analysis and design of pultruded FRP shapes under bending, Compos. Part B-Eng., 27, 295-305, (1995).

3 Davalos, J. F. Salim, H. A. Qiao, P. and Barbero, E. J. Multi-objective material architecture optimization of pultruded FRP I-beams, Compos. Struct., 35, 271-281, (1996).

4 Davalos, J. F. Salim, H. A. and Qiao, P. Flexural-torsional buckling of pultruded fiber reinforced plastic composite Ibeams: experimental and analytical evaluations, Compos. Struct., 38, 241-250, (1997).

5 Davalos, J. F. Salim, H. A. and Qiao, P. and Kiger, S. A. Analysis and design of Fiber Reinforced Plastic composite deck and stringer bridges, Compos. Struct., 38, 295-307, (1997).

6 Upadhyay, A. and Kalyanaraman, V. Simplified analysis of FRP box-girders, Compos. Struct., 59, 217-225, (2003).

7 Kumar, P. Chandrashekhara, K. and Nanni, A. Structural performance of a FRP bridge deck. Constr. Build. Mater., 18, 35-47, (2004).

8 Wael, F. R. Local buckling analysis of pultruded FRP structural shapes subjected to eccentric compression, Thin Wall Struct., 48, 709-717, (2010). 
9 Esfandiari, A. Bakhtiari-Nejad, F. Sanayei, M. and Rahai, A. Structural finite element model updating using transfer function data, Comput. Struct., 88, 54-64, (2010).

10 Hollaway, L. C. A review of the present and future utilisation of FRP composites in the civil infrastructure with reference to their important in-service properties, Const. Building Mater., 24 (12), 2419-2445, (2010).

11 Zimmermann, K. Zenkert, D. and Siemetzki M. Testing and analysis of ultra thick composites, Compos. Part B-Eng, 41 (4), 326-336, (2010).

12 Amir, F. and Kim, Y. J. Numerical analysis of pultruded GFRP box girders supporting adhesively bonded concrete deck in flexure, Eng. Struct., 33, 3527-3536, (2011).

13 Ascione, L. Giordano, A. and Spadea, S. Lateral buckling of pultruded FRP beams, Compos. Part B-Eng, 42, 819824, (2011).

14 Feo, L, Mosallam A. S. and Penna, R. Mechanical behavior of webflange junctions of thin-walled pultruded I-profiles: An experimental and numerical evaluation, Compos. Part B-Eng, 48, 18-39, (2013).

15 Napoli, A. Bank, L. C. Brown, V. L. Martinelli, E. Matta, F. and Realfonzo, R. Analysis and design of RC structures strengthened with mechanically fastened FRP laminates: A review, Compos. Part B-Eng, 55, 386-399, (2013).

16 Gao, Y. Chen, J. Zhang, Z. and Fox D. An advanced FRP floor panel system in buildings, Compos. Struct., 96, 683690, (2013).

17 Cardoso D. C., Harries K. A., Batista E De M. Compressive local buckling of pultruded GFRP I-sections: Development and numerical/experimental evaluation of an explicit equation, ASCE J. Compos. Const., 19 (2), 1-12, (2015).

18 Mottershead, J. E. and Friswell, M. I. Model updating in structural dynamics: a survey, J. Sound Vib., 167 (2), 34775, (1993).

19 De Wilde, W. P. Narmon, B. Sol, H. and Roovers, M. Determination of the material constants of an anisotropic lamina by free vibration analysis, Proceedings of the International Seminar on Modal Analysis, Orlando, Fla, 44-49, (1984).

20 Sol, H. Identification of anisotropic plate rigidities using free vibration data, $\mathrm{PhD}$ dissertation, Vrije Universiteit Brussel, Belgium, (1986).

21 Deobald, L. R. and Gibson, R. F. Determination of elastic constants of orthotropic plates by a modal analysis/Rayleigh-Ritz technique, J. Sound Vib., 124 (2), 269-283, (1988).
22 Grdiac, M. and Paris, P. A. Direct identification of elastic constants of anisotropic plates by modal analysis: theoretical and numerical aspects, J. Sound Vib., 195 (3), 401-415, (1996).

23 Mota Soares, C. M., Moreira, de Freitas M., and Arajo, A. L. Identification of material properties of composite plate specimens, Compos. Struct., 25, 277-285 (1993).

24 Larsson, D. Using modal analysis for estimation of anisotropic material constants, J. Eng. Mech-ASCE, 123 (3), 222-229, (1997).

25 Cugnoni, J. Gmr, T. and Schorderet, A. Inverse method based on modal analysis for characterizing the constitutive properties of thick composite plates, Comput. Struct., 85, 1310-1320, (2007).

26 Collins, J. D. Hart, G. C. Hasselman, T. K. and Kennedy, B. Statistical identification of structures, AIAA Journal, 12 (2), 185-190, (1974).

27 Chen, J. C. and Garba, J. A. Analytical model improvement using modal test results, AIAA Journal, 25 (11), 14941499, (1980).

28 Dascotte, E. Material identification of composite structures from combined use of finite element analysis and experimental modal analysis, Proceedings of the 10th IMAC, 1274-1280, (1992).

29 Mishra, A. K. and Chakraborty, S. Determination of Material Parameters of FRP Plates With Rotational Flexibility at Boundaries Using Experimental Modal Testing and Model Updating, Exp. Mech., 55 (5), 803-815, (2015).

30 Mishra, A. K. and Chakraborty, S. Development of a Finite Element Model Updating Technique for Estimation of Constituent Level Elastic Parameters of FRP Plates, Appl. Math. Comput., 258, 84-94, (2015).

31 FEMtools v3.5.3, Dynamic Design Solutions NV, (2012).

32 Pulse LabShop v13.1.0.246, Bruel and Kjaer, Sound and Vibration Measurement, (2008).

33 ME'scopeVES v4.0.0.96, Vibrant Technology Inc., (2007).

34 ABAQUS v6.9, Dassault Systmes Simulia Corp, (2009).

35 Ewins, D. J. Modal testing: theory and practice, Research Studies Press Ltd., London, (2000).

36 ASTM D3039/D3039M Standard Test Method for Tensile Properties of Polymer Matrix Composite Materials, (2008).

37 Jones, R. M. Mechanics of Composite Materials, McGrawHill, (1999), 2nd ed. 